\title{
The Impact of a Mathematics Bridging Intervention on the Inclusivity of a University Economics Programme
}

\author{
I. Landgärds, Ida.landgards@ uia.no Faculty of Engineering and Science, University of Agder
}

\begin{abstract}
The inclusivity of all students in the University Economics programme is in danger due to a high failure rate in the first-year mathematics course. This study investigates whether participation in a bridging course, and what aspects of it, can contribute to equal opportunities and increased inclusivity in the Mathematics for Economists course, and henceforth reduce the failure rate. It adds to the meager European literature on remedial course effectiveness. Through the use of ordinary least square regression analyses, a significant positive effect of participation in the bridging course was found for the student group as a whole. Furthermore, the results indicated that participation was particularly valuable for the least mathematically prepared students.
\end{abstract}

\section{INTRODUCTION}

It is a general international problem that many economics students lack the mathematics background needed for successful studies at the Business School (Laging and Voßkamp 2017, Opstad and Arethun 2019, Büchele 2020a). In Norwegian Business schools, the mathematical heterogeneity among the first-year students plays out in poor grades and high dropout rates in the Mathematics for Economists course. Especially students who followed the $\mathrm{P}^{1}$-mathematics route in upper secondary school face difficulties (failure rates of about 40\%) (Busch, Olaussen et al. 2017, Landgärds 2019). While according to the fourth sustainability goal, we should seek to ensure inclusive and equitable quality education (Finansdep/Udep 2019), all students need to be given equal opportunities to succeed in their studies once admitted to a university economics programme. Therefore, at the University of Agder, a new blended-learning pre-course intervention, consisting of a diagnostic test in combination with a bridging course, was implemented in 2018. Building on the pedagogical philosophy of Carroll (1989 p.30), which is that "we should seek mainly to achieve equality of opportunity for students," the intention was to ensure that less prepared students would be aware of what mathematics was required, and especially to give them the opportunity to study basic mathematics skills relevant for economics studies, before embarking on the Mathematics for Economists course. The design of the pre-course intervention, illustrated in Figure 1, was presented at the MNT conference 2019 (Landgärds 2019).

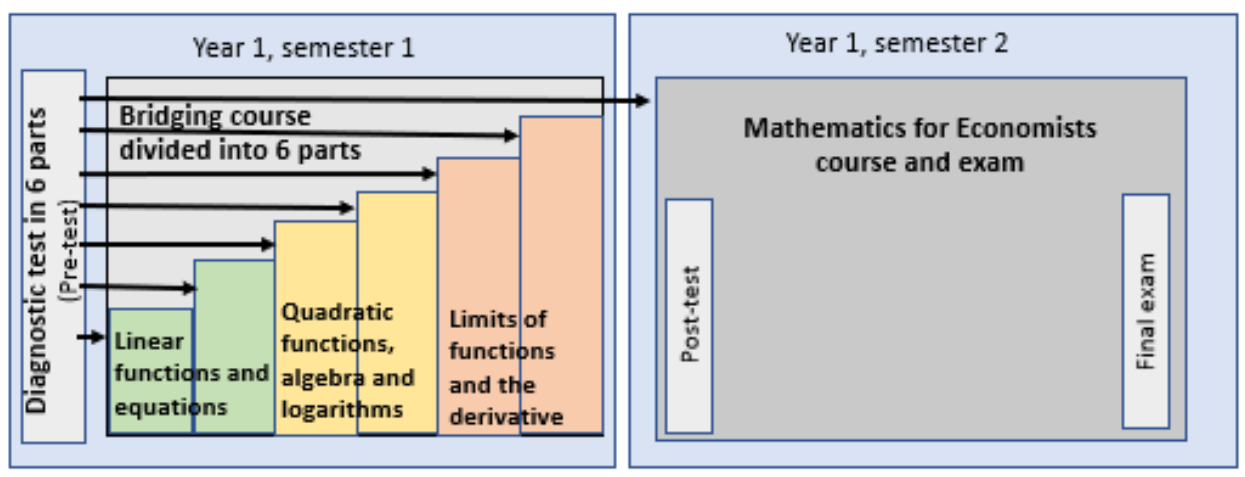

Fig. 1. The pre-course intervention consisting of a diagnostic test guiding the students to the right part(s) of the bridging course, or directly to the Mathematics for Economists course.

\footnotetext{
1 Curriculum in P-mathematics is practical and qualifies candidates for higher education https://www.udir.no/kl06/MAT5-03/Hele/Hovedomraader?lplang=http://data.udir.no/kl06/eng
} 
It is generally assumed that remediation courses have a positive effect on students' mathematics skills and mitigate the heterogeneity of students' mathematics background on entry. However, the effectiveness of remediation is, although extensively investigated within North America, not clear (e.g. Bettinger and Long 2009, Valentine, Konstantopoulos et al. 2017). And corresponding studies within the European higher education system are rare. The transferability of the findings from the North American research is not granted, due to the remedial courses' different structures and conditions such as decentralized courses, voluntary participation and/or the course structure itself (Büchele 2020a). The few European studies show no greater consensus about the effectiveness of remedial mathematics courses for raising student performance within the study of Economics. While Lagerlöf and Seltzer (2009) and Di Pietro (2014) found little or no effect, De Paola and Scoppa (2014), Laging and Voßkamp (2017), (Büchele 2020a) and (Büchele 2020b) found positive effect from participation in a remedial course. Furthermore, to the best of our knowledge, there is no European study investigating the key pedagogical issue of what aspects of remedial courses are important in enhancing student achievement. The purpose of this study is hence to gain an understanding of what aspects of the bridging course can contribute to equal opportunities and increased inclusivity in the Mathematics for Economists course, and henceforth reduce the failure rate. In particular, we investigate what process variables (derived from data about participation in workshops and learning analytics records from the online course platform) predict student achievement on the bridging course post-test and on the Mathematics for Economists course exam.

\section{METHOD}

All first-year economics students in 2018 were required to take an online diagnostic test (pre-test) at the beginning of their first semester. The same test (with items given new numeric values) was then administered at the start of the second semester (post-test) again. The bridging course took a blended learning approach. The pedagogical aspects of interest in our research (process variables) are students' participation in workshops, students' use of training fields (online quizzes with help-options where the student can pause and learn more about how to solve such exercises through videos and written explanations before continuing with the exercise), of written exercises with fully worked solutions, and of written theory documents.

Three achievement variables and four process variables were used in the analysis. The achievement measures for each student were their scores on the pre-test, post-test, and course exam. The process measures for each student were the number of workshops they attended, of training fields where they studied more than $50 \%$ of the tasks provided, of written exercises with worked solutions accessed, and of written theory documents accessed online. Ordinary-least-square regression (OLS) in several hierarchical stages with blockwise entry was found to be the most appropriate method to investigate what process variables (workshops, training, exercises, theory) seem to be of importance for students participating in the bridging course in terms of their performance on the post-test and most importantly on the Mathematics for Economists course exam.

First, the presage variable (prescore) was investigated through regression equation (1). The assumption was that students who studied Pmath in upper secondary school would perform significantly worse on the pre-test than students who studied the more theoretical mathematics route. Second, factoring out the influence of a presage variable, the score on the pre-test (prescore), the final model, where outcome = postscore or examscore, outlined in equation (2) was developed in several steps. The results are discussed in the next section.

$$
\begin{aligned}
& \text { prescore }=b_{0}+b_{1} \text { Pmath }+b_{2} \text { Rmath }+\varepsilon \\
& \text { outcome }=b_{0}+b_{1} \text { prescore }+b_{2} \text { training }+b_{3} \text { theory }+b_{4} \text { exercises }+b_{5} \text { workshops }+\varepsilon
\end{aligned}
$$

\section{RESULTS}

The assumption about the relative weakness of students who had followed the school P-mathematics route was validated as regression equation (1) generated significant $(p<0.001)$ estimates of $b_{0}=$ 32.075 (constant) and $b_{1}=-12.245$ (Pmath coefficient) while $b_{2}=0.405$ (Rmath coefficient) was not significant. The significant negative effect for Pmath arose from such students scoring, on 
average, about 12 points less on the pre-test compared to their peers who studied Smath or Rmath in upper secondary school. The results for the OLS regression analysis for equation (2) was caried out in three hierarchical steps (S1-S3) and are presented in Tables 1 and 2 for the prediction of the shorterterm postscore and the longer-term examscore respectively.

\subsection{Predicting postscore and examscore}

In step 1, the presage variable prescore is significant in predicting both postscore and examscore. While the pre- and the post-test were the 'same' (with respect to questions but new numeric values), the Mathematics for Economists course exam was different with respect to level of mathematics and assessment. Therefore, naturally the portion of variance explained is considerably less (16.9\%) in Table 2 compared to Table $1(38,7 \%)$.

In step 2, the process variables were added into the regression equation (2). In the prediction of postscore, none of the variables reached significance, although the exercises variable did approach significance $(p=0.064)$, but the variance explained increased only marginally. In the prediction of examscore, the explained variance increases significantly by 12.5 percentage points. Moreover, the estimate for the variable training, which is 2.146 reaches significance $(p<0.01)$. The variable training corresponds to the number of training fields where a student tackled more than $50 \%$ of the tasks. The mean use of training fields is 2.33 (SD 2.83). The training coefficient implies that, ceteris paribus, for each additional training field covered by a student (in particular, by crossing the mean from 2 to 3 ) their exam score rises by 2.15 percentage points.

Table 1. Results from regression analyses, stage two. Predicting the dependent variable Postscore

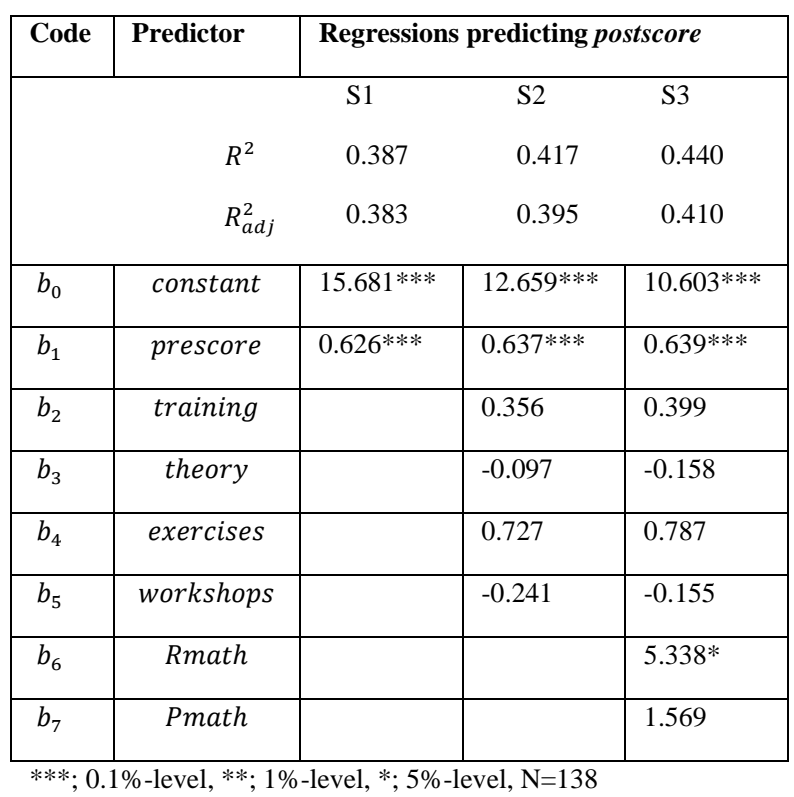

Table 2. Results from regression analyses, stage three. Predicting the dependent variable Examscore

\begin{tabular}{|c|c|c|c|c|}
\hline \multirow[t]{2}{*}{ Code } & \multirow[t]{2}{*}{ Predictor } & \multicolumn{3}{|c|}{ Regressions predicting examscore } \\
\hline & & S1 & S2 & S3 \\
\hline & $R^{2}$ & 0.169 & 0.294 & 0.356 \\
\hline & $R_{a d j}^{2}$ & 0.163 & 0.267 & 0.322 \\
\hline$b_{0}$ & constant & $46.097 * * *$ & $29.014 * * *$ & $45.324 * * *$ \\
\hline$b_{1}$ & prescore & $0.951 * * *$ & $1.037 * * *$ & $0.748 * * *$ \\
\hline$b_{2}$ & training & & $2.146^{* *}$ & $2.146^{* *}$ \\
\hline$b_{3}$ & theory & & 0.632 & 1.566 \\
\hline$b_{4}$ & exercises & & 1.816 & 1.557 \\
\hline$b_{5}$ & workshops & & 0.414 & 0.103 \\
\hline$b_{6}$ & Rmath & & & -8.839 \\
\hline$b_{7}$ & Pmath & & & $-18.575 * * *$ \\
\hline
\end{tabular}

In step 3, students school mathematics background is accounted for. Interestingly, the variable Pmath is significant in the examscore model but not the postscore one. Given the close resemblance of pre-test and post-test, the absence of any (additional) Pmath effect in step 3 is not surprising. Nor, given the considerable difference between pre-test and exam, is the emergence in step 3 of a (further) Pmath effect.

\subsection{Further investigations of the process variables}

As the interest of this study is particularly in examining the process variables and how students can benefit from participating in the bridging course, it was important to further investigate the process effect. The process variables were combined into one single 'participation' variable taking values from 0 to 33. The variable was found to be significant in predicting both prescore and examscore. Furthermore, an interaction term, formed as the product of the participation variable and the dummy variable Pmath, was added into the regression equation to enable investigation of whether 
participation had a larger effect on the outcome variables for Pmath students. The interaction term was significant in predicting examscore, indicating that the benefit from participation in the bridging course was greater for students from P-mathematics. The results are presented in Tables 3 and 4.

Table 3. Predicting postscore using the merged process variable participation

\begin{tabular}{|c|c|c|c|c|}
\hline Code & Predictor & Regression & redicting & tscore \\
\hline & & S1* & S2* & S3* \\
\hline & $R^{2}$ & 0.406 & 0.429 & 0.429 \\
\hline & $R_{a d j}^{2}$ & 0.398 & 0.412 & 0.407 \\
\hline$b_{0}$ & constant & $12.184 * * *$ & $\begin{array}{l}10.473 * * \\
*\end{array}$ & $10.011 * *$ \\
\hline$b_{1}$ & prescore & $0.654 * * *$ & $0.652 * * *$ & $0.656 * * *$ \\
\hline$b_{2}$ & participation & $0.238^{*}$ & $0.266 *$ & 0.297 \\
\hline$b_{3}$ & Rmath & & $5.264 *$ & $5.325^{* *}$ \\
\hline$b_{4}$ & Pmath & & 1.322 & 2.199 \\
\hline$b_{5}$ & $\begin{array}{l}\text { participation } \\
\times \text { Pmath }\end{array}$ & & & -0.066 \\
\hline
\end{tabular}

Table 4. Predicting examscore using the merged process variable participation

\begin{tabular}{|c|c|c|c|c|}
\hline \multirow[t]{2}{*}{ Code } & Predictor & \multicolumn{3}{|c|}{ Regressions predicting examscore } \\
\hline & & S1* & $\mathrm{S} 2 *$ & S3* \\
\hline & $R^{z}$ & 0.282 & 0.271 & 0.274 \\
\hline & $R$ & 0.342 & 0.322 & 0.350 \\
\hline$b_{0}$ & constant & $26.562 * * *$ & $40.690 * * *$ & $50.922 * * *$ \\
\hline$b_{1}$ & prescore & $1.108^{* * * *}$ & $0.840 * * *$ & $0.742 * * *$ \\
\hline$b_{2}$ & participation & $1.329 * * *$ & $1.457 * * *$ & $0.785^{*}$ \\
\hline$b_{3}$ & Rmath & & -8.285 & -9.636 \\
\hline$b_{4}$ & Pmath & & $-17.538 * * *$ & $-36.950 * * *$ \\
\hline$b_{5}$ & $\begin{array}{l}\text { participation } \\
\times \text { Pmath }\end{array}$ & & & $1.473^{*}$ \\
\hline
\end{tabular}

\section{REFLECTIONS}

The mathematics pre-course intervention aimed to increase equity and inclusion amongst first-year students in the economics programme. Our study showed that while none of the individual process variables proved a good predictor, this was not because there was no process effect of participation in the bridging course, but because these individual variables did not provide strong enough signals of such effects. The existence of a process effect was established by forming the composite participation variable which positively and significantly predicted both postscore and examscore.

Because the failure rate in the Mathematics for Economists course has, in the past, been particularly high for students who followed the P-mathematics route at school, we further investigated the benefit to this group from participation in the bridging course. The significant positive interaction term indicated that participation contributed an extra 1.47 percentage points increase in examscore for every additional unit of the participation measure. To illustrate this more concretely, consider the effect of the interaction term, for participation at three different levels (average, +1SD and -1SD), for the Pmath students, as elaborated in Table 5. The effect is investigated for two different prescore values: the mean (27.45 points) and one standard deviation below the mean (14.96 points). These values were chosen to roughly to represent the 'relatively strong' Pmath student and the 'average' Pmath student as $85 \%$ of the Pmath students scored below the mean and 36\% scored below -1SD on the pre-test.

Table 5. Predicted examscore values at three different levels of participation for two different prescore values when Pmath $=1 . N=138$.

\begin{tabular}{|l|l|l|l|}
\hline \multirow{2}{*}{ Prescore } & \multicolumn{3}{|l|}{ Predicted examscore at three different levels of participation } \\
\cline { 2 - 4 } & $-1 \mathrm{SD}$ & Average & $+1 \mathrm{SD}$ \\
\hline Mean & $43 \%$ & $60 \%$ & $77 \%$ \\
\hline$-1 \mathrm{SD}$ & $34 \%$ & $51 \%$ & $68 \%$ \\
\hline
\end{tabular}

The pass/fail threshold for the Mathematics for Economists course exam was 40\%. From Table 5, we can conclude that participation in the bridging course plays a particularly important role for Pmath students scoring lower on the pre-test, for example one standard deviation below the mean. For such a 
student, low participation in the bridging course (one standard deviation below average, equating to making use of only 4 units of the course) is predicted to lead to an exam score of $34 \%$, a clear failure. By comparison, average participation (equating to making use of $35 \%$ of the resources available in the bridging course) is predicted to lead to a score of 51\%, a very comfortable pass. Those Pmath students with an average prescore are predicted to pass whatever their level of participation, if only very narrowly (43\%) with low participation. The benefits of stronger participation are markedly higher levels of capability, with predicted exam scores of $60 \%$ for average participation, and $77 \%$ for higher participation.

The results hence indicate a positive participation effect on the examination score, and hence, arguably, increased inclusivity of all students. However, the process variables need to be further investigated to give additional insight into important aspects of the bridging course.

\section{ACKNOWLEDGEMENTS}

Thanks to students being willing to participate in this study. Thanks to Kirsten Bjørkestøl and my Supervisors Kenneth Ruthven and Rolf Nossum for valuable comments in the writing process. Also, thanks to MatRIC for funding the work.

\section{REFERENSES}

Bettinger, E. P. and B. T. Long (2009). "Addressing the needs of underprepared students in higher education does college remediation work?" Journal of Human resources 44(3): 736-771.

Busch, T., et al. (2017). Matematikkens betydning for suksess ved $\varnothing$ konomisk-administrative studier. Bred og Spiss NTNU handelshøyskolen 50 år. L. Opstad. Bergen, Fagbokforlaget.

Büchele, S. (2020a). "Bridging the gap-How effective are remedial math courses in Germany?" Studies in educational evaluation 64: 100832 .

Büchele, S. (2020b). "Should we trust math preparatory courses? An empirical analysis on the impact of students' participation and attendance on short-and medium-term effects." Economic Analysis and Policy.

Carroll, J. B. (1989). "The Carroll Model:A 25-Year Retrospective and Prospective View." Educational researcher 18(1): 26-31.

De Paola, M. and V. Scoppa (2014). "The effectiveness of remedial courses in Italy: a fuzzy regression discontinuity design." Journal of Population Economics 27(2): 365-386.

Di Pietro, G. (2014). "The Short-term Effectiveness of a Remedial Mathematics Course: Evidence from a UK University." The Manchester School 82(3): 363-384.

Finansdep/Udep (2019). One year closer 2019 - Norway`s progress towards the implementation of the 2030 Agenda for Sustainable Development

Lagerlöf, J. N. M. and A. J. Seltzer (2009). "The Effects of Remedial Mathematics on the Learning of Economics: Evidence from a Natural Experiment." The Journal of Economic Education 40(2): 115-137.

Laging, A. and R. Voßkamp (2017) Determinants of Maths Performance of First-Year Business Administration and Economics Students. International Journal of Research in Undergraduate Mathematics Education 3, 108-142

Landgärds, I. (2019). "Providing economics students opportunities to learn basic mathematics." Nordic Journal of STEM Education 3(1): 185-189.

Opstad, L. T. and T. Årethun (2019). "Choice of Courses in Mathematics at Upper-Secondary School and Attitudes towards Mathematics among Business Students. The case of Norway."

Valentine, J. C., et al. (2017). "What happens to students placed into developmental education? A meta-analysis of regression discontinuity studies." Review of educational research 87(4): 806-833. 